\title{
HIV in pregnancy: a 9 year study of the seroprevalence, sociodemographic factors and pregnancy outcomes of seropositive women at a tertiary care hospital in Mumbai, Maharashtra, India
}

\author{
Michelle N. Fonseca, Nishita A. Mehta*
}

Department of Obstetrics and Gynecology, Lokmanya Tilak Municipal Medical College and General Hospital, Sion, Mumbai, Maharashtra, India

Received: 20 August 2019

Accepted: 29 August 2019

\section{*Correspondence:}

Dr. Nishita A. Mehta,

E-mail: nishimehta103@gmail.com

Copyright: () the author(s), publisher and licensee Medip Academy. This is an open-access article distributed under the terms of the Creative Commons Attribution Non-Commercial License, which permits unrestricted non-commercial use, distribution, and reproduction in any medium, provided the original work is properly cited.

\section{ABSTRACT}

Background: HIV can cause considerable morbidity and mortality in those affected. An effective PPTCT programme helps in reducing the spread of HIV by vertical transmission and improving the life of the women and her baby.

Methods: A retrospective study was done at a tertiary care hospital, including pregnant women registered and delivered at the hospital during a period of 9 years from January 2010 to December 2018. Pretest counseling, HIV testing, Post-test counseling were done and antiretroviral prophylaxis given as per the NACP guidelines. Sociodemographic characteristics, obstetric and maternal-foetal outcome of seropositive women and efficacy of PPTCT services were analyzed.

Results: Out of the 58,205 antenatal mothers included, 55,256 (94.93\%) accepted HIV testing. 171 of these tested positive $(0.31 \%) .70$ spouses of the 171 seropositive women tested positive, 53 tested negative and 48 did not undergo the HIV test. Majority of seropositive women were primigravidas; housewives from urban areas, from low income and educational background and with no history of any contraceptive use. $7.6 \%$ had an MTP, $1.75 \%$ a spontaneous abortion and $0.58 \%$ an ectopic pregnancy. Of the 154 births, 35.71\% underwent caesarean sections. There were $96.7 \%$ live births in our study and the perinatal mortality rate was 5.19\%. After 2013, all mother-baby pairs were given ARV prophylaxis.

Conclusions: Utilization of PPTCT services has increased through the years, decreasing the vertical transmission and seroprevalence rate. Increasing the acceptance rates of HIV testing, both by patients and partners may further help in curbing the spread of this condition.

Keywords: Antenatal women, Human immunodeficiency virus, HAART, PPTCT, Seroprevalence

\section{INTRODUCTION}

HIV is a worldwide menace that has reached pandemic proportions at an alarmingly fast pace. India has a large proportion of these cases, estimated to be around 21.40 lakh with more than $42 \%$ of the total estimated people living with HIV (PLHIV) being females. ${ }^{1}$ It is estimated that without any intervention the risk of vertical transmission is $20-45 \%$, being the primary route of transmission of HIV among children. ${ }^{2}$ Thus early diagnosis, treatment with Highly Active Antiretroviral Treatment (HAART), and prevention of spread of the virus are the need of the hour. Prevention has to start at a basic grass root level of educating the public, and especially high risk and vulnerable groups about the existence of such a disease, modes of spread and 
measures that can be taken to prevent it. The Government of India launched the National AIDS Control Programme (NACP) in 1992, as a comprehensive programme for the prevention and control of HIV/ AIDS in India. The NACP instituted prevention of parent to child transmission (PPTCT) of HIV in 2001-02 to provide HIV testing and treatment to all pregnant women registered for antenatal care (ANC). ${ }^{1}$ Antiretroviral (ARV) prophylaxis, which initially constituted a single dose of nevirapine given at the time of delivery, was changed to a more efficacious multi-drug ARV regimen, based on the new WHO guidelines of $2013 .{ }^{3}$ Lifelong HAART (triple drug regimen) was initiated to all pregnant and breastfeeding women living with HIV regardless of their CD4 count or WHO clinical stage- for their own health, to prevent vertical transmission and for additional HIV prevention benefits. ${ }^{4}$ These recommendations were a pivotal reform, reducing the risk of mother-to-child-transmission to less than 5 percent in breastfeeding populations. ${ }^{1}$

Numerous organizations, worldwide and in India, are ardently working in this field. UNAIDS aims to end HIV pandemic by 2030 , adopting $90-90-90$ strategy, ie. $90 \%$ of PLHIV know their status, $90 \%$ of diagnosed PLHIV are on treatment and $90 \%$ of PLHIV on treatment achieve an undetectable viral load by $2020 .^{5}$ The goals of the national PPTCT programme in India are primary prevention of HIV, especially in women of child-bearing age, integration of PPTCT services, sexual reproductive health and family planning, early infant diagnosis (EID), pediatric ART and adolescent reproductive and sexual health (ARSH), TB and STI/RTI services and strengthening post-natal care of the HIV-infected mother and her exposed infant.

According to the latest HIV estimations report, around 87,000 new HIV infections and 69,000 AIDS-related deaths occurred in 2017 and 22,677 pregnant women needed ART to prevent mother-to-child transmission of HIV. State-wise, the PPTCT need was highest in Maharashtra followed by Uttar Pradesh, Bihar, Andhra Pradesh, Karnataka, Telangana, West Bengal, Gujarat, Tamil Nadu and Rajasthan. Together, these 10 States contributed to almost three fourth of the total PPTCT need in the country. ${ }^{1}$

Our study aims to determine the seroprevalence of HIV in antenatal women, the socio-demographic factors of seropositive women and the utilization and efficacy of PPTCT services to minimize the risk of mother to child transmission at our centre, one of the largest tertiary care hospitals in Mumbai.

\section{METHODS}

This was a retrospective observational study done at a tertiary care hospital in Mumbai. Study population comprised of all newly registered pregnant women attending antenatal care clinic during a period of 9 years, from January 2010 to December 2018. Thus, 58,205 antenatal women were included in the study.

All of these women underwent pretest counseling with 'opt out' option, HIV testing, if they consented, using 3 different rapid tests and post-test counseling, which was done by trained personnel as per the NACP guidelines. Sociodemographic data, medical and obstetric history were gathered, and partner testing offered. In seropositive women, information about MTP services was given to those who wanted termination of pregnancy and advice on regular follow up at ANC and ART centre was given to all. Institutional delivery was recommended to those who wanted continuation of pregnancy. Those who delivered before 2013 were given prophylactic single dose Nevirapine therapy at the time of delivery and from 2013, they were started on multidrug ART regimen, as per the new WHO guidelines. Obstetric and maternalfoetal outcome of the seropositive women was analyzed, maintaining confidentiality throughout. Simple statistical methods like mean, percentage and proportion were utilized to analyze results.

\section{RESULTS}

A total of 58,205 antenatal mothers were included in the study, of which all underwent pre-test counseling. 55,256 (94.93\%) accepted HIV testing. Some of their reasons for refusing testing were testing done in the past, fear of knowing they were positive or presence of a negative report from elsewhere. 171 of these tested positive for HIV, giving a seroprevalence rate of $0.31 \%$. Anteretroviral (ARV) prophylaxis was commenced in all of them, as per the new guidelines from 2013 onwards. Prior to that $96 \%$ were given nevirapine prophylaxis in labour.

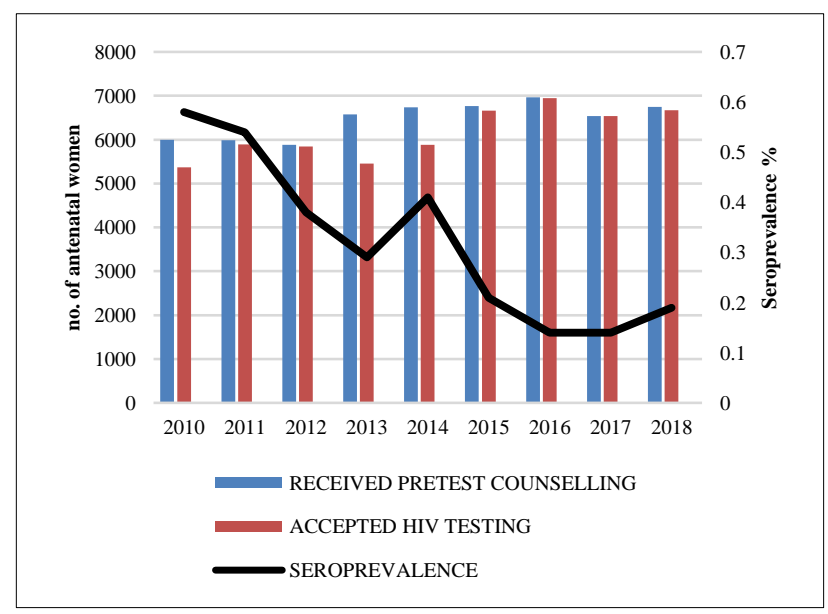

Figure 1: Acceptance rate of HIV testing among antenatal women and seroprevalence.

From 2010 to 2018, the acceptance rate of HIV was testing, i.e. the number of antenatal women accepting the HIV test out of the total antenatal women receiving pretest counseling, showed an overall increase, as shown in Figure 1. The seroprevalence, in general showed a 
decreasing trend through the years, from $0.58 \%$ in 2010 to $0.19 \%$ in 2018 .

The husbands of seropositive patients were counselled and $71.93 \%$ agreed to undergo the HIV test. 70 spouses of the 171 seropositive women tested positive, 53 tested negative and 48 did not undergo the HIV test. There was, in general, a declining trend amongst the number of spouses not tested, indicating increased efficacy of the PPTCT services in partner identification and testing. The overall rate of discordant couples in our study, where the partner of an HIV positive woman was HIV negative, was $30.9 \%$. As elicited in Figure 2, the proportion of discordant couples increased through the years, (implying that the women could have acquired the virus through sources other than their husbands such as blood/blood products, other sexual partners, vertical transmission or iv drug users). Thus, the importance of dual protection, i.e. using condoms with another method of contraception, to prevent the spread of the infection to their partners, needs to be emphasized more.

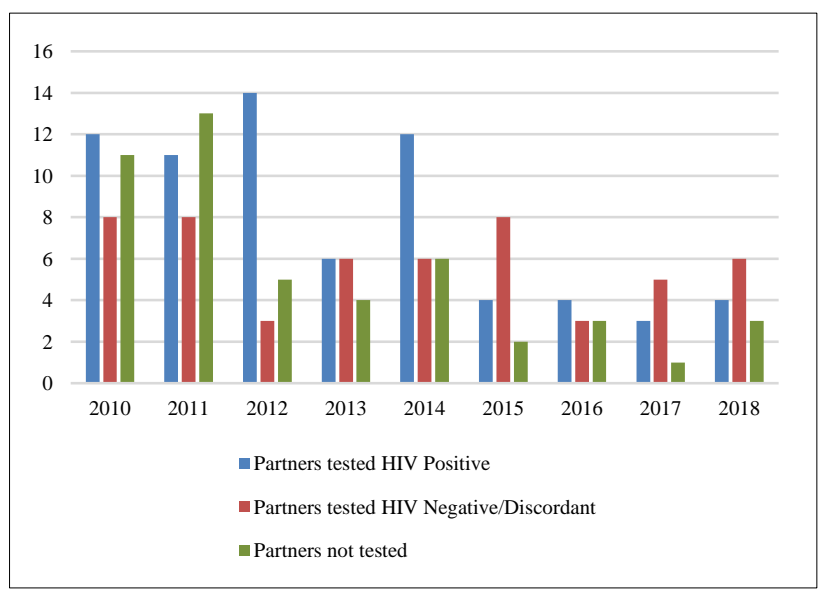

Figure 2: Testing among partners of seropositive women.

We observed that majority of seropositive women were housewives residing in urban areas (ie. Mumbai), without any addictions, from low income classes, with a very poor educational background and lack of knowledge about HIV and AIDS, as depicted in Table 1. 50.88\% were primigravidas and majority registered their pregnancy in their second or third trimester, with only $11.7 \%$ coming for their first visit in the first trimester. $81.29 \%$ revealed that husbands had addictions to alcohol/tobacco/illicit drugs. A staggering $76.61 \%$ of the women tested positive did not use any form of contraception, indicating the urgent need to spread awareness about HIV, targeting not only the pregnant women of the lower socioeconomic classes, but also their non-pregnant counterparts and male members of the society. Most were in the 20-25 year age group, with $13.45 \%$ being under 20 , thus it is imperative that knowledge about HIV and modes of spread be imparted from a younger age, along with sex education and safe sex practices, through mass media and awareness campaigns.

Table 1: Sociodemographic characteristics of seropositive women.

\begin{tabular}{|c|c|c|c|}
\hline \multicolumn{2}{|c|}{ Sociodemographic factors } & $\begin{array}{l}\text { No. of } \\
\text { women }\end{array}$ & Percentage \\
\hline \multirow{3}{*}{ Age } & $<20$ & 23 & $13.45 \%$ \\
\hline & $20-25$ & 106 & $61.99 \%$ \\
\hline & $>25$ & 42 & $24.56 \%$ \\
\hline \multirow{3}{*}{ Occupation } & Housewife & 152 & $88.89 \%$ \\
\hline & Service & 8 & $4.68 \%$ \\
\hline & Labourer & 11 & $6.43 \%$ \\
\hline \multirow{3}{*}{ Religion } & Hindu & 67 & $39.18 \%$ \\
\hline & Muslim & 89 & $52.05 \%$ \\
\hline & Others & 15 & $8.77 \%$ \\
\hline \multirow{2}{*}{ Residence } & Urban & 112 & $65.50 \%$ \\
\hline & Rural & 59 & $34.50 \%$ \\
\hline \multirow{4}{*}{ Education } & Illiterate & 61 & $35.67 \%$ \\
\hline & $\begin{array}{l}\text { Primary } \\
\text { school }\end{array}$ & 78 & $45.61 \%$ \\
\hline & $\begin{array}{l}\text { Secondary } \\
\text { school }\end{array}$ & 26 & $15.20 \%$ \\
\hline & Graduate & 6 & $3.50 \%$ \\
\hline \multirow{2}{*}{$\begin{array}{l}\text { Per capita } \\
\text { income }\end{array}$} & $<2000 / \mathrm{mth}$ & 107 & $62.57 \%$ \\
\hline & $>2000 / \mathrm{mth}$ & 64 & $37.43 \%$ \\
\hline \multirow{2}{*}{ Gravida } & Primigravida & 87 & $50.88 \%$ \\
\hline & Multigravida & 84 & $49.12 \%$ \\
\hline \multirow{3}{*}{$\begin{array}{l}\text { Trimester of } \\
\text { pregnancy } \\
\text { registered }\end{array}$} & First & 20 & $11.70 \%$ \\
\hline & Second & 106 & $61.99 \%$ \\
\hline & Third & 45 & $26.32 \%$ \\
\hline \multirow{4}{*}{$\begin{array}{l}\text { Contraceptive } \\
\text { practice }\end{array}$} & Condoms & 28 & $16.37 \%$ \\
\hline & OCPS & 8 & $4.68 \%$ \\
\hline & IUDS & 4 & $2.34 \%$ \\
\hline & None & 131 & $76.61 \%$ \\
\hline \multicolumn{4}{|l|}{ Addictions } \\
\hline \multirow{2}{*}{ Wife } & Yes & 19 & $11.11 \%$ \\
\hline & No & 152 & $88.89 \%$ \\
\hline \multirow{2}{*}{ Husband } & Yes & 139 & $81.29 \%$ \\
\hline & No & 32 & $18.71 \%$ \\
\hline
\end{tabular}

Table 2: Obstetric outcome in seropositive women.

\begin{tabular}{|lll|}
\hline Obstetric outcome & $\begin{array}{l}\text { No. of } \\
\text { patients }\end{array}$ & $\begin{array}{l}\text { Percentage } \\
\text { MTP }\end{array}$ \\
\hline Spontaneous/missed abortion & 3 & $7.60 \%$ \\
\hline Ectopic & $1.75 \%$ \\
\hline Total births & $0.58 \%$ \\
\hline Vaginal delivery & 154 & \\
\hline LSCS & 99 & $64.29 \%$ \\
\hline
\end{tabular}

With regards to obstetric outcome in the seropositive women (Table 2), 7.6\% opted for MTP, $1.75 \%$ had a spontaneous abortion and $0.58 \%$ were diagnosed to have an ectopic pregnancy. Thus, the total births were 154 , out 
of which 99 delivered vaginally (64.29\%) and 55 underwent caesarean sections $(35.71 \%)$. Table 3 shows the maternal and foetal/ neonatal outcome of the seropositive women. There were 5 intrauterine deaths or stillbirths and out of the live-births, $30.87 \%$ were preterm. There were 29 NICU admissions (19.46\%) and 3 babies $(2.01 \%)$ died within the first 7 days of birth. $23.98 \%$ of seropositive women had opportunistic infections like candidiasis or kochs, either in their antenatal or postnatal period. All live babies born were given ARV prophylaxis. HIV testing using dried blood spot (DBS) was done in $96.64 \%$ babies. Prior to 2013 , when the old treatment regimen was prevalent, $4.26 \%$ of babies tested positive. From 2013 onwards, once the mothers were started on the multi-drug ARV regimen only $2.32 \%$ babies tested positive, that too, one each in 2013 and 2014. All babies 2015 onwards tested HIV negative, elucidating the success of the new treatment regimen and the PPTCT programme.

\section{Table 3: Maternal and foetal/ neonatal outcome in} seropositive women.

\begin{tabular}{|lll|}
\hline $\begin{array}{l}\text { Maternal-fetal } \\
\text { outcome }\end{array}$ & $\begin{array}{l}\text { No. of patients/ } \\
\text { newborn }\end{array}$ & Percentage \\
\hline $\begin{array}{l}\text { Opportunistic infections } \\
\text { (maternal) }\end{array}$ & $41 / 171$ & $23.98 \%$ \\
\hline Preterm live birth & $46 / 149$ & $30.87 \%$ \\
\hline Full term live birth & $103 / 149$ & $69.13 \%$ \\
\hline IUFD/stillbirth & $5 / 154$ & $3.23 \%$ \\
\hline NND (within 7 days) & $3 / 149$ & $2.01 \%$ \\
\hline PNMR rate & $8 / 154$ & $5.19 \%$ \\
\hline NICU admission & $29 / 149$ & $19.46 \%$ \\
\hline IUFD: Intrauterine foetal & death, NND: Neonatal death, \\
\hline PNMR: Perinatal mortality rate, NICU: Neonatal ICU
\end{tabular}

\section{DISCUSSION}

In our study, the pretest counseling rate was $100 \%$ and 94.93\% accepted HIV testing. Shiradkar et al, reported an acceptance rate of HIV testing of $72.0 \%$, Kwatra et al, $82.48 \%$ and Radhika et al, $91 \% .^{6-8}$

As seen in our study, Mohite et al, also reported an increase in the acceptance rate of pretest counseling and HIV testing, from $88.9 \%$ to $100 \%$ over 10 years. ${ }^{9}$

The seroprevalence rate in our study was low compared to other studies, as shown in Table 4.

There has been an overall decrease in the seroprevalence rate in HIV positive antenatal women in India, from $0.48 \%(52,806)$ in 2007 to $0.21 \%(22,677)$ in 2017 , with Maharashtra having the highest number of HIV positive ANC women- 2406 out of a total of 22,677 all over India. ${ }^{1,14}$ Our study too, shows that the seroprevalence among ANC women has diminished through the years, from 0.58 in 2010 to 0.19 in 2018 . Mohite et al, reported a decline from $2 \%$ in 2003 to $0.2 \%$ in $2012 .^{9}$
$71.93 \%$ of partners of the HIV positive antenatal women underwent HIV testing in our study, and $56.91 \%$ of those tested were HIV positive. In studies done by Shiradkar et al, and Dadhwal et al, $76.95 \%$ and $80 \%$ partners tested positive respectively. ${ }^{6,15}$ Mohite et al reported a partner testing rate of $54.9 \%$, with an increasing trend of acceptance over the years, as stated in our study. ${ }^{9}$

In our study $50.88 \%$ of the antenatal seropositive mothers were primigravidas, with majority being housewives from low income classes, with a very poor educational background. Most of the women themselves denied any addictions but $81.29 \%$ revealed that husbands had addictions to alcohol/tobacco/illicit drugs. $76.61 \%$ of the women tested positive did not use any form of contraception. Most lived in an urban area, since our study was conducted in a tertiary hospital in Mumbai, the largest metropolitan of India.

In a study done by Kwatra et al, $95.86 \%$ were married, majority were primigravidas (43.44\%) with low socioeconomic status (77.93\%), housewife by occupation (67.58\%), having no addictions $(86.20 \%)$ and with no contraceptive use $(72.41 \%)$, which complied with our study. ${ }^{7}$ The study population in their study were women from rural Maharashtra, hence majority were Hindu $(79.31 \%)$ rural $(81.37 \%)$ women. Potty et al, also found that majority of the seropositive women were uneducated housewives. ${ }^{16}$ The general trend observed is that most seropositive women are from a low socioeconomic class with a lack of knowledge about HIV, thus widespread education to the masses in a language they understand and using such a method that they will accept and comply to the information given is the need of the hour, such as group counseling with husbands, in-laws and other family members.

In our study, $7.6 \%$ opted for MTP, $1.75 \%$ had a spontaneous abortion and $0.58 \%$ an ectopic pregnancy. From the 154 seropositive women that gave birth; $64.29 \%$ had vaginal deliveries and $35.71 \%$ had caesarean sections. There were 5 intrauterine deaths or stillbirths and of all the live-births, $30.87 \%$ were preterm. There were 29 NICU admissions (19.46\%) and 3 babies (2.01\%) died within the first 7 days of birth. The perinatal mortality rate in our study, ie. among the babies born to seropositive mothers was $5.19 \%$, which was significantly greater than the PNMR rate of $3.07 \%$ in the HIV negative women delivering at our institute over the same period of time. Similarly, the stillbirth rate was also greater in the seropositive women- $3.23 \%$, compared to $2.20 \%$ in seronegative women. There were also more preterm births in the seropositive population $(30.87 \%)$ compared to the seronegative women $(22.70 \%)$.

In a study done by Shiradkar et al, $10.29 \%$ of seropositive women had an abortion and caesarean section rates declined from $50 \%$ to $31 \%$ from 2002 to $2011 .^{6}$ In a study done by Kwatra et al, there were $11.53 \%$ abortions, and $76.15 \%$ delivered vaginally and $12.30 \%$ by 
Caesarean section. ${ }^{7}$ Radhika et al, reported an abortion rate of $10.3 \%$, and caesarean section rate of $43.6 \% .^{8} \mathrm{We}$ had a NICU admission rate of $19.46 \%$, whereas Dadhwal et al, had a NICU admission rate of $8.5 \% .^{15}$

Table 4: Seroprevalence in pregnant women in various studies from India.

\begin{tabular}{|lllll|}
\hline Study & Location & Sample size & Seroprevalence & Period of study \\
\hline Our study & Mumbai & 58,205 & $0.31 \%$ & $2010-18$ \\
\hline Nayak et al & Cuttack, Odisha & 1600 & $0.5 \%$ & 2014 \\
\hline Mehta et al $^{11}$ & Jodhpur, Rajasthan & 40,913 & $0.16 \%$ & $2013-15$ \\
\hline Radhika et al $^{8}$ & Delhi & $2,52,447$ & $0.1-0.25 \%$ & $2002-15$ \\
\hline Mohite et al $^{9}$ & Rural Maharashtra & 32,575 & $0.8 \%$ & $2003-12$ \\
\hline Shah et al & Mumbai & 123,439 & $1.4 \%$ & $1993-2004,2008$ \\
\hline Sarkate et al & & 31,609 & $0.88 \%$ & $2008-12$ \\
\hline
\end{tabular}

Stillbirth rate in our study was $3.23 \%$, compared to $6.9 \%$ reported by Radhika et al, and $2 \%$ by Potty et al. ${ }^{8,16}$

There were $96.77 \%$ live births in our study as compared to $93.91 \%$ in the study done by Kwatra et al, and $93.12 \%$ reported by Shiradkar et al. ${ }^{6,7}$

We reported $100 \%$ ART coverage of antenatally registered HIV-positive pregnant women at our institute, 2013 onwards, which surpasses the target of $>95 \%$ set by the WHO.

All the newborns in our study were given nevirapine prophylaxis. In the study done by Kwatra et al, $86 \%$ of women and $80 \%$ of newborns received Nevirapine prophylaxis. $^{7}$ Mohite et al, reported that $86.1 \%$ of mother-baby pairs received nevirapine prophylaxis. ${ }^{9}$

\section{CONCLUSION}

As depicted by our study, the seroprevalence rate in antenatal women has decreased through the years, and utilization of PPTCT services has increased, reflecting the success of the national PPTCT programme and the PPTCT centre at our institute. It is still an uphill task to strive towards elimination of mother to child transmission of HIV, and certain areas and sociodemographic groups need special attention. Educating and empowering women and creating awareness about HIV in the general public to overcome the social stigma attached to this disease, increasing the uptake of HIV testing, especially among spouses and specialized antenatal and postnatal care are some measures that can help.

Funding: No funding sources

Conflict of interest: None declared

Ethical approval: The study was approved by the Institutional Ethics Committee

\section{REFERENCES}

1. National AIDS Control Organization and ICMRNational Institute of Medical Statistics. HIV
Estimations 2017: Technical Report. New Delhi: NACO, Ministry of Health and Family Welfare, Government of India, 2018. Available at: http://naco.gov.in/sites/default/files/HIV\%20Estimati ons\%202017\%20Report_1.pdf.

2. NACO Guidelines for prevention of mother to child transmission of HIV: Ministry of Health and Family Welfare, Government of India. Available at: http://naco.gov.in/prevention-parent-childtransmissionpptct.

3. Consolidated guidelines on the use of Antiretroviral drugs for treating and preventing HIV infection, Recommendations for a public health approach, 2013: World Health Organization. Available at: https://www.who.int/hiv/pub/guidelines/arv2013/en.

4. Updated Guidelines for Prevention of Parent to Child Transmission (PPTCT) of HIV using Multi Drug Anti-retroviral Regimen in India: NACO, Ministry of Health and Family Welfare, Government of India, 2013. Available at: http://naco.gov.in/sites/default/files/National_Guideli nes_for_PPTCT_0.pdf.

5. UNAIDS. 90-90-90: an ambitious treatment target to help end the AIDS epidemic. Geneva: UNAIDS; 2014. Available at: https://www.unaids.org/en/resources/documents/201 7/90-90-90.

6. Shiradkar S, Mande S, Bapat G, Setia MS. Is it time to bring the "parent" into the prevention of parent to child transmission programs in India? A study of trends over a 10-year period in a prevention of parent to child transmission clinic in India. Indian journal of sexually transmitted diseases and AIDS. 2016;37(1):58.

7. Kwatra A, Bangal VB, Shinde KK, Padaliya K. HIV seroprevalence among the pregnant population and utilisation of ICTC facilities at a teaching hospital in Rural Maharashtra. AMJ. 2011;4(10):566-70.

8. Radhika AG, Chawla S, Bhaskaran S. Prevention of parent to child transmission of HIV: single centre experience of 14 years at tertiary care hospital in Delhi, India. J Clin Diagn Res. 2017;11(8):QC04QC07. 
9. Mohite RV, Mohite VR. Performance of the prevention of parent to child transmission program: a decadal trend from rural Maharashtra, India. Indian $\mathrm{J}$ Sexually Trans Dis AIDS. 2016;37(1):52.

10. Nayak AK, Jain MK, Dhivya S, Hota S. A study on prevalence of HIV infection among pregnant women attending antenatal clinic in a tertiary care hospital, Cuttack, India. Int J Comm Med Pub Health. 2017;4(5):1504-9.

11. Mehta S, Balgopal B, Mehta L. Seroprevalence of HIV in ANC clinic attendees and utilization of PPTCT services at a tertiary care hospital of Western Rajasthan, India. Int J Reprod Contracept Obstet Gynecol. 2017;6:1590-5.

12. Shah I, Lala M, Damania K. Prevalence of HIV infection in pregnant women in Mumbai, India: Experience from 1993-2004 and 2008. J Family Med Prim Care. 2017;6(2):240-2.

13. Sarkate $P$, Paranjpe $S$, Ingole $N$, Mehta $P$. Monitoring HIV epidemic in pregnant women: are the current measures enough? J Sex Transm Dis. 2015;2015:194831.

14. HIV sentinel surveillance and HIV estimation in India 2007: a technical brief, department of AIDS control. Ministry of Health and Family Welfare. NACO Annual Report, 2007. Available at: http://naco.gov.in/sites/default/files/HIV\%20Sentinel $\% 20$ Surveillance $\% 20$ and $\% 20 \mathrm{HIV} \% 20$ Estimation $\% 2$ 02007_A\%20Technical\%20Brief.pdf.

15. Dadhwal V, Sharma A, Khoiwal K, Deka D, Sarkar P, Vanamail P. Pregnancy outcomes in HIV-infected women: experience from a tertiary care center in India. Int J MCH AIDS. 2017;6(1):75.

16. Potty RS, Sinha A, Sethumadhavan R, Isac S, Washington R. Incidence, prevalence and associated factors of mother-to-child transmission of HIV, among children exposed to maternal HIV, in Belgaum District, Karnataka, India. BMC Public Health. 2019;19(1):386.

Cite this article as: Fonseca MN, Mehta NA. HIV in pregnancy: a 9 year study of the seroprevalence, sociodemographic factors and pregnancy outcomes of seropositive women at a tertiary care hospital in Mumbai, Maharashtra, India. Int J Reprod Contracept Obstet Gynecol 2019;8:3852-7. 